\title{
Entre VHILS e os Jerónimos: arte urbana de Lisboa enquanto objeto turístico
}

\section{Between VHILS and the Jerónimos: Lisbon's urban art as a tourist object}

\section{Ricardo Campos*}

* Universidade Nova de Lisboa - Lisboa, Portugal

Pesquisador associado ao CICSNova rmocampos@yahoo.com.br https://orcid.org/0000-0003-4689-0144

\section{Ágata Sequeira**}

** Universidade Nova de Lisboa - Lisboa, Portugal Pesquisadora associada ao CICSNova agata.sequeira@gmail.com https://orcid.org/0000-0002-3615-9457 


\title{
Resumo
}

Diversas cidades têm incluído a arte urbana como parte das suas estratégias de promoção e planeamento turístico. Este facto deriva de uma gradual valorização social e legitimação institucional deste tipo de expressões estéticas presentes no espaço público. Em muitas cidades deparamo-nos, hoje, com processos de turistificação da arte urbana, uma dinâmica que está dependente de um conjunto de atores sociais. A turistificação da arte urbana tem consequências, não só ao nível da constituição da oferta turística da cidade, mas também ao nível das relações e interações que se estabelecem entre operadores e guias, turistas, artistas, instituições e comunidades locais. Com este artigo pretendemos refletir sobre a articulação entre a arte urbana e o sector turístico, partindo de um conjunto de dados preliminares de natureza qualitativa recolhidos no âmbito de um projeto em curso sobre arte urbana em Lisboa.

Palavras-chave: arte urbana; turismo; Lisboa; mundo da arte.

\begin{abstract}
Several cities have included urban art as part of their tourism promotion and planning strategies. This fact derives from a gradual social valorization and institutional legitimation of this type of aesthetic expressions present in the public space. In many cities, we are now faced with processes of touristification of urban art, a dynamic that is dependent on a set of social actors. The touristification of urban art has consequences not only in terms of the constitution of the tourist offer of the city, but also in the relations and interactions that are established between operators and guides, tourists, artists, institutions and local communities. With this article we intend to reflect on the articulation between urban art and the tourism sector, starting from a set of preliminary data of a qualitative nature collected in the framework of an ongoing project on Urban Art in Lisbon.
\end{abstract}

Keywords: urban art; tourism; Lisbon; artworld. 


\section{Introdução}

A mundialmente famosa editora de guias de viagem Lonely Planet lançou em 2017 uma publicação com o título Street art. Este livro pretende ser um roteiro para visitar a melhor arte urbana existente no planeta. Este facto é relevante na medida em que representa mais um exemplo do papel central que a arte urbana tem vindo a assumir para a imagem e identidade de muitas cidades, mas principalmente porque é revelador do peso crescente que esta expressão da vida urbana contemporânea tem em termos turísticos. A indústria turística tem estado atenta a este fenómeno. No mesmo ano, um artigo da responsabilidade do editor da plataforma online Eturbonews - Global Travel Industry News, tinha por título "New travel trend: Exploring cities through graffiti and street art" (New..., 2017). Neste texto era salientado o papel que o graffiti e a street art desempenham nas cidades, o que tem levado as autoridades a criar condições para que estes possam florescer de forma controlada, favorecendo a imagem do território e incentivando o turismo.

Na verdade, ao viajarmos por diferentes cidades em redor do planeta, notamos de imediato como é comum a presença de múltiplas expressões visuais de rua, que vão das mais simples e informais até às mais sofisticadas e protegidas. Estas manifestações tornaram-se parte integrante da paisagem, convivendo com o edificado, com o espaço público e o património urbano. São, por isso, uma parte singular dos modos de vida locais, tendo adquirido crescente relevo enquanto manifestações de cultura popular ou de genialidade artística. A sua gradual legitimação por parte de instâncias oficiais e de diferentes sectores da sociedade muito contribuiu para o peso que atualmente detêm.

Apesar de existirem diversas evidências que corroboram o papel detido pela arte urbana na construção da imagem das cidades e na sua promoção no exterior, facto que tem impacto ao nível do turismo, esta é uma matéria ainda pouco explorada. Porém, nos últimos anos, foram surgindo alguns textos que lidam ora com a questão específica do muralismo (Koster; Randall, 2006; McDowell, 2008; Miguel-Molina et al., 2013; Poon, 2016; Santamarina-Campos et al., 2017), ora com a da arte urbana (Andron, 2018; Banet-Weiser, 2011; Campos; Sequeira, 2019; Jażdżewska, 2017; Mokras-Grabowska, 2014). Grande parte da literatura reflete sobre o valor e potencial deste tipo de expressões visuais urbanas, entendendo-as como uma mais-valia das 
cidades e das comunidades. A sua capitalização do ponto de vista turístico representa o corolário de um processo de legitimação, institucionalização e mercantilização deste tipo de expressões urbanas. Vários autores têm vindo, precisamente, a debruçar-se sobre esta reconfiguração simbólica das expressões de rua e sobre a sua capitalização económica, nomeadamente quando esta é aplicada no âmbito de uma retórica que assenta na ideia de cidade criativa enquanto motor de desenvolvimento urbano (Mould, 2015; Schacter, 2014). De acordo com uma visão razoavelmente consensual, a aposta nas artes e na cultura revela-se central para o propósito de regeneração urbana, para a reconfiguração da imagem das cidades e para a sua revitalização enquanto território dinâmico, contemporâneo, cosmopolita.

Consideramos que não existe ainda um debate sólido sobre o assunto que permita aferir os processos e impactos ligados à turistificação da arte urbana. Com este artigo pretendemos trazer um contributo para uma maior problematização em torno deste fenómeno, partindo do caso concreto de Lisboa. Propomos uma problematização que tenha em consideração os diferentes atores sociais envolvidos neste processo. A base empírica que serve para a redação deste artigo resulta de um projeto atualmente em curso $^{1}$ sobre a arte urbana na cidade de Lisboa. Para análise das questões relativas ao turismo, foi definido um processo de recolha de dados que passou, em primeiro lugar, pela realização de entrevistas semiestruturadas e da observação etnográfica de tours especializados neste campo (entre 2017 e 2018) e, em segundo lugar, pela consulta de fontes documentais diversas, online e impressas (media, guias turísticos, plataformas online de serviços turísticos, documentos de entidades governamentais).

\section{Uma breve definição de arte urbana}

Aquilo que atualmente denominamos de arte urbana provém de um conjunto de dinâmicas sociais e de expressões estéticas que surgiram na última metade do século passado, tendo uma origem marcadamente informal e, em grande parte dos casos, ilegal. O graffiti urbano, surgido no final da década de 1960

1 TransUrbArts - projeto financiado pela FCT/MEC (IF/O1592/2015). O CICS.NOVA/FCSH-UNL é também financiado por fundos nacionais através FCT/MEC (UID/SOC/04647/2013). 
nos EUA e que se expandiu por todo o globo está largamente documentado na literatura especializada (Campos, 2010, 2013; Castleman, 1982; Cooper; Chalfant, 1984; Ferrell, 1996; Lewisohn, 2008; Macdonald, 2001). Algo que a literatura mais recente também tem vindo a descrever é uma alteração de certa forma radical desta situação, com uma crescente legitimação, institucionalização e mercantilização destas expressões urbanas informais (Austin, 2010; Bengtsen, 2014; Campos, 2015; Kramer, 2010; Schacter, 2014; Sequeira, 2016a; Waclawek, 2011). Para tal em muito contribuiu o fenómeno de artificação (Shapiro, 2012) do graffiti e de algumas intervenções de rua informais. A artificação, neste caso, significa que uma manifestação comunicativa originalmente de natureza popular e ilícita, socialmente desvalorizada, passa gradualmente a ser coletivamente apreciada pelas suas qualidades estéticas. Este é, como defende Shapiro (2012), um processo social em que participam um conjunto de atores sociais. Em consonância com esta dinâmica surgem com algum vigor no final do século XX e início do século XXI expressões como pós-graffiti ou street art. Neste artigo optámos pelo termo "arte urbana", por ser mais abrangente e, também, por ter um cunho institucional e formal que lhe foi sendo atribuído em tempos mais recentes.

O conceito de arte urbana é, então, algo difuso e fonte de controvérsia. Este facto é, em parte, consequência da frequente confusão e sobreposição com termos que lhe são próximos, como sejam graffiti, street art ou pós-graffiti. Tendo, por outro lado, uma base genética marcadamente não-oficial e rebelde, é natural que resista às classificações promovidas pelas entidades oficiais e pelos poderes. As classificações podem ser, em muitos casos, entendidas como formas de domesticação e enclausuramento, manobras promovidas pelos poderes para regular os formatos mais selvagens e inclassificáveis de manifestação pública. No entanto, não podemos ignorar que é precisamente isso que acontece quando o termo "arte urbana" se converte numa categoria socialmente legitimada e aprovada por múltiplas instituições (políticas, económicas, artísticas). $\mathrm{O}$ facto de ser concebido como uma forma de Arte (com A maiúsculo) também tem fortes ressonâncias normativas, na medida em que pressupõe uma aprovação social, uma avaliação de gosto realizada por diferentes instâncias com poder para conceder valor simbólico aos artefactos estéticos.

Entendemos, por isso, a arte urbana como um "mundo da arte" (Becker, 2010) numa abordagem que destaca o papel que diferentes atores sociais desempenham 
na produção social da arte (Campos; Sequeira, 2018). Assim, para a sua afirmação colaboram atores tão distintos como os artistas, os media, as autarquias, os galeristas, os críticos de arte, mas igualmente os agentes turísticos, com um contributo importante para a legitimação e institucionalização do campo (Andron, 2018; Young, 2014). Sendo razoavelmente recente, a arte urbana pode-se considerar um movimento artístico ainda em construção, com fronteiras algo elásticas e permeáveis, compreendendo um conjunto diversificado de expressões (graffiti, street art, muralismo, culture jamming, guerilla gardening, etc.) e de técnicas (stencil, paste-up, stickers, spray painting, reverse graffiti, etc.). Aquilo que transmite unidade e coerência a este movimento artístico é que ele surge e ganha visibilidade no espaço público urbano, facto que determina que seja frequentemente denominado como uma arte de rua. Todavia, como diversos autores têm feito notar (Bengtsen, 2014; Campos, 2017; Campos; Sequeira, 2018, 2019; Sequeira, 2016b), a rua deixou de ser o campo exclusivo de ação destes atores, sendo que a galeria e o mercado da arte são, cada vez mais, campos relevantes para a construção de carreiras. É neste sentido que Banet-Weiser (2011) considera a arte urbana como um exemplo atual da "cultura de convergência", no sentido em que há diversos fatores, entidades, atores e sectores que contribuem para os processos de transformação a que tem vindo a ser sujeita: legitimação, artificação, turistificação, etc.

Na última década inúmeros projetos, exposições, festivais e eventos em torno destas manifestações têm acontecido em grandes cidades mundiais. ${ }^{2}$ Para além do mundialmente famoso Banksy, muitos outros artistas foram ganhando relevo, transformando este campo num dos mais mediatizados e acessíveis em termos de disseminação das produções artísticas. Nomes como Os Gêmeos, Kobra, JR, Blu, Shepard Fairey, Swoon, C215, Slinkachu, ou os portugueses VHILS e Bordalo II, têm tido grande exposição mediática, fruto de

2 Há um conjunto de exposições que merece ser destacado: Spank the monkey, que esteve patente entre 2006 e 2007 no BALTIC Centre for Contemporary Art Gateshead (UK); a exposição Street art, de 2008 na Tate Modern; a exposição de Bansky em 2009 no Bristol City Museum; a exposição da Fundação Cartier Born in the streets - graffiti, entre 2009 e 2010; e a exposição Art in the streets, no Museum of Contemporary Art em Los Angeles (MOCA) em 2011. Mais recentemente, Street art - Banksy \& Co, em Bolonha em 2016, ou a exposição Art from the streets, em Singapura, em 2018. Também é de notar a abertura do maior museu exclusivamente dedicado aos street artists, o Urban Nation, em Berlim. No caso português, são de destacar as exposições de artistas de arte urbana na Galeria Vera Cortês, desde 2006, e na Galeria Underdogs, a partir de 2013, bem como a exposição dos Gêmeos (CCB, 2010) ou a do VHILS no Museu da Eletricidade (2014), entre outras. 
trabalhos e exposições realizadas em vários países. Este facto também tem consequências em termos nacionais. Uma breve pesquisa em torno dos eventos de arte urbana em Portugal revela um mapa extremamente ativo e diversificado, sendo que inúmeros municípios têm desenvolvido ou apoiado múltiplas iniciativas neste campo, nomeadamente festivais (ver Figura 1, que diz respeito a um festival organizado pela Câmara Municipal de Lisboa). De destacar o facto de estar anunciado para breve a abertura do Museu de Arte Urbana e Contemporânea de Cascais, um dos poucos museus no mundo dedicados a este movimento artístico, ${ }^{3}$ o que diz bem do processo de institucionalização em curso.

A valorização da arte urbana no espaço público tem sido associada ao sucesso da retórica da cidade criativa que, entretanto, se disseminou nas últimas décadas e que colocou as artes, a cultura e a criatividade no centro do debate sobre o desenvolvimento económico das cidades (Mould, 2015). Há, deste modo, cada vez mais uma estratégia deliberada de produção da paisagem que tem em consideração a gestão das expressões visuais de rua, seja por um lado pela irradicação e perseguição de alguns formatos, seja pela promoção e visibilização de outros. Daí que McAuliffe (2012) fale de geografias morais ao abordar esta questão, indicando que há sempre uma avaliação social sobre aquilo que se encontra deslocado (out of place), que é tido como não pertencendo a um certo lugar. Tal era o significado tradicionalmente atribuído ao graffiti ilegal, classificado como uma forma de vandalismo e poluição visual. Todavia, segundo o mesmo autor, as geografias morais da cidade criativa são outras, uma vez que, como demonstra, a ressignificação do graffiti e de práticas artísticas associadas permite a sua capitalização através de políticas culturais assentes na ideia de cidade criativa. Ou seja, aquilo que há umas décadas atrás estava out of place e era classificado como vandalismo, atualmente é visto como potencialmente interessante e como uma mais-valia para o lugar. Daí que, não obstante a crescente aposta por parte das instituições na promoção das expressões reguladas e comissionadas de arte urbana, a cidade continua a acolher obras de natureza informal e não-autorizada (ver Figura 2). Estas manifestações, não só estão na base da singularidade deste movimento, como continuam a ser uma fonte inesgotável de criatividade e reconhecimento público.

3 Este museu resulta de uma parceria entre o Município de Cascais e o artista visual VHILS. 


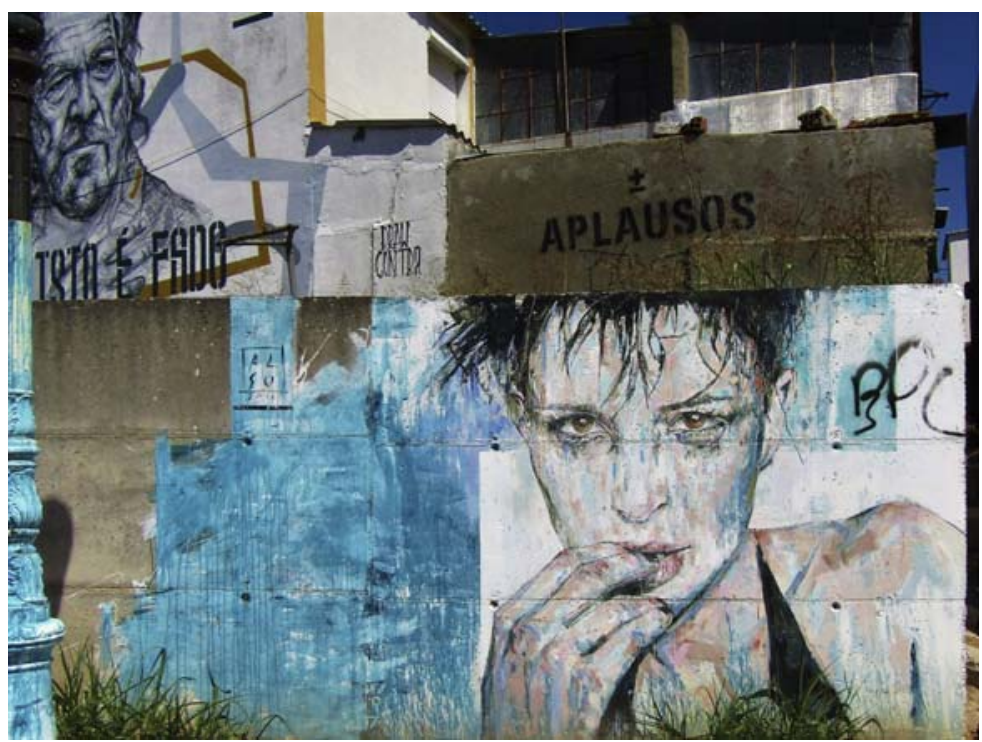

Figura 1. Exemplo de arte urbana comissionada: festival Muro, Bairro Padre Cruz, Lisboa (foto: Ágata Sequeira).

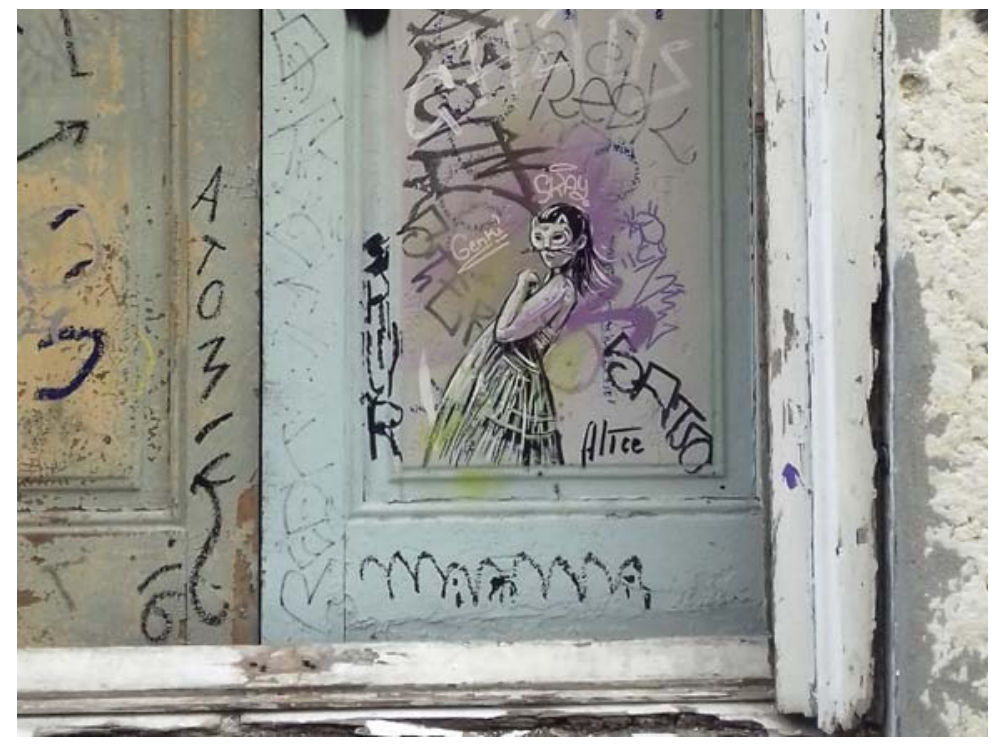

Figura 2. Exemplo de arte urbana informal: intervenção de Alice Pasquini no Bairro Alto, Lisboa (foto: Ágata Sequeira). 


\section{Arte urbana e turismo cultural}

O sector do turismo é, do ponto de vista económico, cada vez mais importante a nível global, sendo de crucial importância para determinados países e regiões. Segundo dados da OMT (Observatório do Turismo de Lisboa, 2017), em 2017 o crescimento do turismo mundial foi na ordem dos 7\%. Em Portugal o sector do turismo está em franco crescimento, particularmente nos últimos anos. Segundo o Turismo de Portugal este sector representa a maior atividade económica em termos de exportações, equivalendo a cerca de 17\% das exportações nacionais (Estratégia..., 2017). A esta situação não será alheia a visibilidade crescente do país nos media internacionais, particularmente no que toca à questão turística. E os media têm divulgado os muitos galardões que o país tem ganho. Na edição de 2018 dos World Travel Awards (WTA),, Portugal foi eleito o "Melhor Destino Europeu", tendo Lisboa sido consagrada com o prémio correspondente para a categoria de destinos urbanos. Na edição de 2017 dos WTA, Portugal havia recebido o prémio de "Melhor Destino Turístico do Mundo", tendo Lisboa vencido o galardão para "Melhor Destino de City Break", bem como o de "Melhor Destino para Cruzeiros" e "Melhor Porto de Cruzeiros".

O turismo tendo por destino específico as cidades também tem vindo a crescer nos últimos anos. ${ }^{6}$ Neste mercado global as cidades têm procurado cativar mais turismo e investimento através de diversas estratégias de city marketing (ou city branding), construindo uma determinada imagem da cidade que se imponha pela sua singularidade (Riza; Doratli; Fasli, 2012). De relevância fundamental para a construção da imagem das cidades contemporâneas é o sector criativo, cultural e artístico. Do ponto de vista turístico, este é um capital crucial num mercado global altamente competitivo (Marques; Richards, 2014).

No âmbito do turismo citadino, deve destacar-se o denominado turismo cultural. Esta vertente turística, cujo crescimento tem vindo a ser assinalável nas últimas décadas, assume-se agora como um elemento fundamental no consumo internacional de turismo, já não sendo um nicho no âmbito

4 Ver https://www.worldtravelawards.com/.

5 Tendo estes dois últimos galardões vindo a ser atribuídos a Lisboa várias vezes desde 2009.

6 De acordo com os dados publicados no European cities marketing benchmarking report 2014 (Turismo de Portugal, 2015). 
das atividades turísticas globais (Du Cros; McKercher, 2002; Richards, 2018; Smith, 2003). Richards (2018) relata que o relatório da Organização Mundial de Turismo (World Tourism Organization, 2018), confirma o papel central do turismo cultural, ocupando uma fatia de $39 \%$ das chegadas internacionais com propósitos turísticos, sendo também uma prioridade para a grande maioria das entidades nacionais dedicadas ao turismo.

O turismo cultural capta a abrangência do que é a noção de cultura, incluindo expressões artísticas complexas, mas também os modos de vida das pessoas (Smith, 2003). A definição que Richards (2018, p. 13) propõe para turismo cultural vai de encontro a esta ideia de abrangência:

Cultural tourism is a type of tourism activity in which the visitor's essential motivation is to learn, discover, experience and consume the tangible and intangible cultural attractions/products in a tourism destination.

Há no turismo cultural uma procura dos aspetos quotidianos locais, uma vontade de aproximação dos turistas aos modos de vida dos lugares que visitam, pelo que a busca pela "autenticidade" se tornou um factor fundamental neste tipo de turismo (Smith, 2003) e que surge a par com o receio de que, com a globalização, as experiências e atividades culturais se tornem "estandardizadas".

O contexto da arte urbana parece especialmente adequado a estas novas formas de turismo citadino. Em primeiro lugar, está associado a uma certa ideia de singularidade e autenticidade locais. Por um lado, as expressões de arte urbana são geralmente produzidas por artistas locais e envolvem um conjunto de temáticas, iconografia e técnicas com uma certa especificidade. Por outro lado, estas expressões estão integradas no território, sendo elemento fundamental da paisagem, da arquitetura e da vivência quotidiana dos seus habitantes. Em segundo lugar, estas são ainda expressões que só recentemente adquiriram algum relevo, razão pela qual ainda não foram amplamente mediatizadas e massificadas enquanto experiência turística. Deste modo, proporcionam atividades de natureza mais excecional, em torno de territórios menos turísticos e conhecidos das cidades, bem como o contacto com outras vivências urbanas. Quando olhamos para os discursos dos media e dos agentes turísticos, essas são precisamente as ideias mais fortemente associadas à promoção e divulgação da arte urbana enquanto produto turístico. 
De forma sucinta convém indicar que os diferentes agentes turísticos têm revelado maior atenção a este campo, existindo evidências claras de que esta é uma área nova e em ampliação. Para além dos casos citados na introdução deste artigo, poderíamos destacar outros exemplos recentes. Em 2017, o site Tourism Review News publicava um artigo enaltecendo a importância da arte urbana, pegando no exemplo concreto da cidade de Berlim (Morris, 2017). As principais editoras de literatura de viagens e turismo começaram a prestar maior atenção ao potencial da arte urbana para o turismo citadino. Passou a ser comum, em muitos guias, haver secções dedicadas à arte urbana, principalmente em cidades onde esta tem uma presença mais forte. Num artigo de 2013 a Fodor's Travel afirmava:

The best art isn't always behind velvet ropes. Graffiti, once a punishable act of pavement protest, has become a bona fide art form. It's been the subject of major exhibitions at institutions like London's Tate Modern and MOCA in Los Angeles, and has turned taggers like Banksy and Shepard Fairey into international superstars. (Saladino, 2013).

Da escassa produção científica publicada sobre a intersecção entre arte urbana e turismo, são de destacar as pesquisas que se debruçam sobre o caso específico do muralismo. Esta é uma forma de manifestação artística geralmente entendida no âmbito do património histórico local, geralmente de índole popular, ligado à identidade cultural, política e simbólica das comunidades. A importância dos murais para o turismo cultural tem vindo a ser salientada, daí que Skinner e Jolliffe (2017, p. 9) falem da existência de um "turismo muralista":

This form of niche tourism specifically consists of visiting locations and destinations with murals. A variety of organized murals tourism products have been developed for consumption, ranging from both guided and self-guided murals tours to murals festivals to murals souvenirs such as postcards, books and t-shirts.

Podemos referir, a título de exemplo, os casos de Penang na Malásia (Poon, 2016), das comunidades Saskatchewan no Canadá (Koster; Randall, 2006) ou de certas comunidades uruguaias (Miguel-Molina et al., 2013) onde se desenvolveu um tipo de turismo em que o muralismo detém um papel significativo. Num âmbito um pouco distinto, é de referir também a importância dos 
murais políticos, como no caso de Orgosolo na Sardenha (Cozzolino, 2014) ou da Irlanda do Norte (McDowell, 2008).

O tema da turistificação de arte urbana enquanto objeto de estudo é relativamente recente. Todavia, alguma da produção neste campo merece ser destacada. Alguns textos revelam a importância que este tipo de arte pode ter para o desenvolvimento turístico e económico de uma região. Jażdżewska, (2017) e Mokras-Grabowska (2014) partindo do exemplo da cidade de Lodz na Polónia, referem o sucesso do turismo de arte urbana numa cidade pós-industrial, privada de património histórico e paisagístico significativo. O relevante neste caso relatado é que a turistificação ocorre a partir de uma estratégia de produção comissionada de murais, no âmbito da Urban Forms Foundation, que organiza festivais de arte urbana e contribui decisivamente para a mudança da paisagem da cidade. Outro tema que tem vindo a ganhar relevo diz respeito, especificamente, ao caso dos tours de arte urbana. É o caso de Andron (2018) ou de Bengtsen (2014) que notam que este tipo de tours se tem vindo a tornar comum em vários centros urbanos.

\section{Lisboa e a turistificação da arte urbana}

Nesta última secção iremos centrar-nos, enfim, sobre o processo social que conduz à fabricação da arte urbana enquanto produto de consumo turístico no caso de Lisboa. Falamos de "turistificação" enquanto processo social através do qual algo que tinha pouco ou nenhum interesse do ponto de vista turístico se converte, gradualmente, num recurso com potencial turístico. A turistificação envolve múltiplas dimensões, que vão do simbólico (reconfiguração simbólica das práticas, objetos, etc.) ao político (legitimação, consagração e proteção de práticas, bens, etc.), passando necessariamente pelo económico (criação de um mercado e exploração económica de práticas, objetos, etc.). Este processo acompanha, muitas vezes, outros processos paralelos, como acontece no caso do objeto de estudo em análise, em que claramente assistimos a dinâmicas de artificação, patrimonialização, mercantilização, etc. destas expressões visuais urbanas.

$O$ projeto de pesquisa anteriormente referido, TransUrbArts, envolve um conjunto de eixos de problematização da arte urbana, sendo que uma das dimensões trabalhadas foi a do turismo. Uma análise deste sector e da sua interligação com o domínio da arte urbana permitiu-nos identificar uma série 
de atores sociais que, através das suas iniciativas, cooperam para a construção da arte urbana enquanto produto turístico. Consideramos que, neste campo, existem atores nacionais e internacionais (ver Quadro 1). Em termos internacionais, devemos ter em conta principalmente o sector da comunicação, fundamental ao nível dos discursos e da construção de narrativas. Neste sector destacamos o sector de atividade da publicação sobre turismo (particularmente os media e os guias turísticos); os media generalistas; e, finalmente, os denominados social media (blogs, redes sociais, etc.).

Falemos um pouco dos media. A arte urbana tem estado presente nos media generalistas, especialmente nas suas secções dedicadas à cultura, lazer e viagens. Vários artigos são anualmente escritos elaborando rankings e hierarquias da arte urbana mundial (Sequeira, 2016a). Algumas cidades são recorrentes no top das cidades internacionais. Nos últimos anos, por exemplo, Lisboa tem figurado nesta lista restrita, sendo destacada em diferentes plataformas de notícias (tais como The New European, The Guardian ou Huffington Post). ${ }^{7}$ Mas a visibilidade destas questões não passa apenas pelos media tradicionais. Não podemos ignorar o papel cada vez mais significativo que os media digitais e as redes sociais desempenham em termos turísticos (Chung; Koo, 2015; Zeng; Gerritsen, 2014). Como tal, são uma fonte de informação muito relevante para quem faz turismo de forma independente (Xiang et al., 2015). E neste caso também encontramos diversos blogs, websites, etc. em que a arte urbana é destacada como um recurso importante das cidades.

Para além destes atores internacionais, existe um conjunto de atores nacionais que tem um papel crucial não apenas na criação de condições para a produção de arte urbana, mas também na sua exploração em termos políticos, económicos e simbólicos. Assim, em termos nacionais, devemos ter em consideração não apenas a comunidade artística, mas principalmente as entidades públicas (locais e nacionais) e os empreendedores locais. Nesta secção iremos detalhar o papel que estes detêm, partindo do caso concreto de Lisboa, com o objetivo de demonstrar que a turistificação da arte urbana nesta cidade é o corolário de um conjunto de processos sociais, políticos e económicos de nível muito distinto e com impactos diferenciados.

7 Ver Porrit (2017), Moore (2017) e Rojo e Harrington (2014). 
Argumentamos que a arte urbana se assume, hoje, como uma marca distintiva da capital lisboeta e que tal resulta de um processo com pouco mais de uma década. Na verdade, na base de todo este processo está, desde logo, uma comunidade artística muito dinâmica que, sendo proveniente do meio do graffiti ou de outros campos culturais e artísticos, tem deixado a sua marca visível na cidade. Deste modo, a paisagem lisboeta é bastante rica do ponto de vista deste tipo de expressões, que tanto podem ser de natureza informal e ilegal, como podem envolver obras encomendadas, comissionadas e reguladas. No entanto, para que a arte urbana na cidade atingisse este patamar foi importante um conjunto de outros atores (ver Quadro 1).

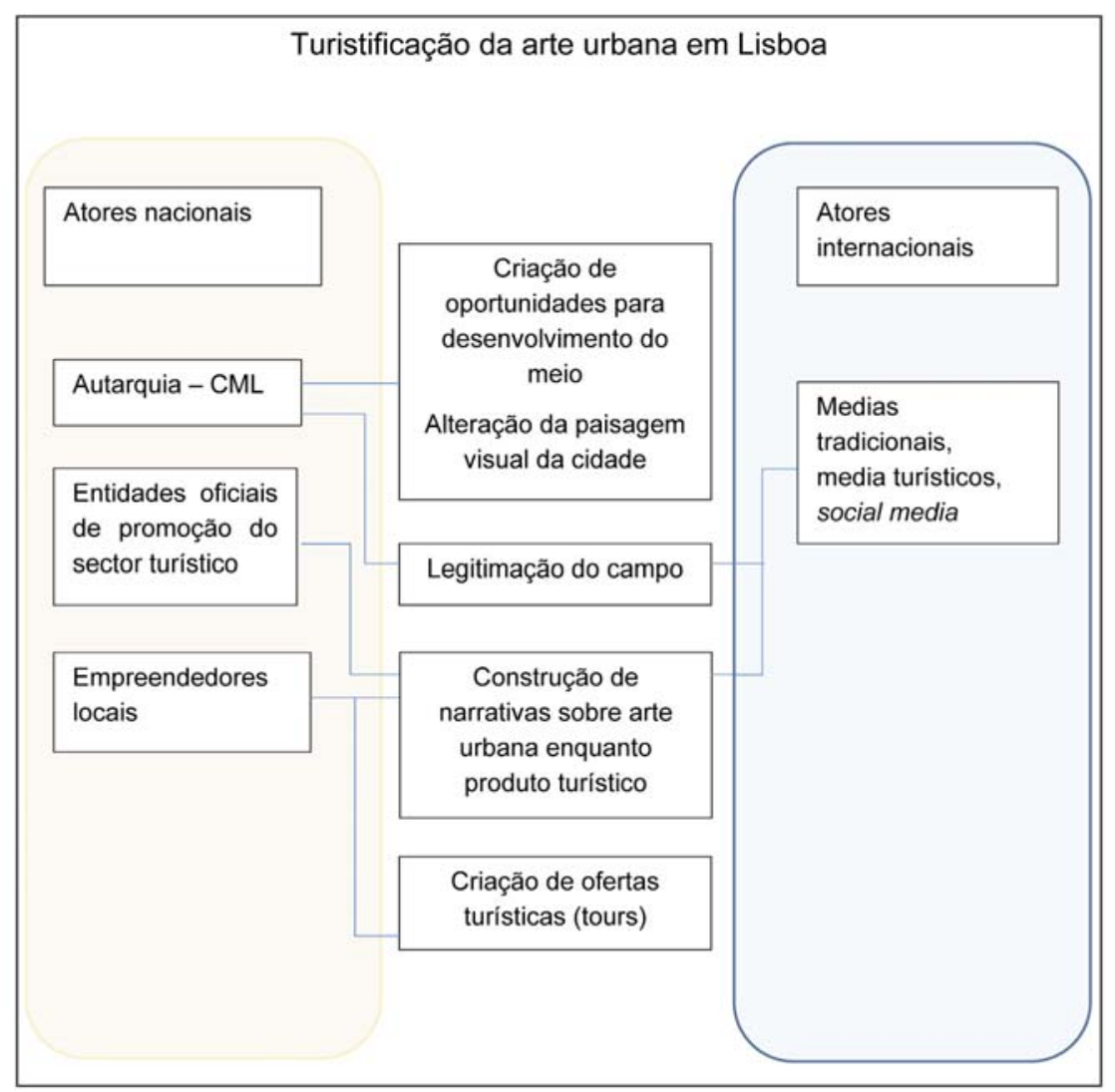

Quadro 1. Turistificação da arte urbana (atores e processos) (Campos; Sequeira, 2019). 
Frisamos que esta é uma expressão de natureza visual com características singulares. Para além de ser contemporânea, é de natureza efémera e, muitas vezes, informal e imprevisível. Desta forma, escapa completamente à natureza do património cultural e arquitetónico da cidade, sedimentado ao longo do tempo. Como tal, para que num tão curto espaço de tempo a arte urbana adquirisse um papel tão significativo, foi fundamental, em primeiro lugar, a criação de um conjunto de condições materiais para o desenvolvimento desta expressão e, em segundo lugar, uma reconfiguração simbólica (ao nível dos discursos públicos) envolvendo estas práticas e estes atores. Os media, a academia e as autarquias foram determinantes na gradual alteração do discurso e na legitimação deste movimento a nível nacional. Apesar de reconhecermos a importância destes elementos, neste artigo iremos centrar-nos principalmente nas entidades públicas (Câmara Municipal de Lisboa, Turismo de Lisboa e Turismo de Portugal) e nos empreendedores locais.

\section{Entidades públicas}

No caso de Lisboa, a autarquia desempenha um papel crucial para a promoção da arte urbana, sendo que podemos enquadrar a sua atuação a dois níveis. Por um lado, na criação de condições materiais (logísticas, financeiras, etc.) para que a comunidade de artistas ${ }^{8}$ se consolidasse e desenvolvesse a sua prática na cidade e, por outro lado, na legitimação, valorização e institucionalização de um movimento que era algo marginalizado. O poder local desempenhou um papel pivô na promoção e expansão desta comunidade artística local, e particularmente na alteração da paisagem urbana, com a multiplicação de obras autorizadas. Assim sendo, o fenómeno da turistificação foi claramente precedido

8 Neste artigo não tivemos por propósito desenvolver uma análise em torno dos artistas associados a este movimento, que foi objeto de outra publicação recente (Campos; Sequeira, 2018). Podemos, no entanto, afirmar que sendo este um movimento multifacetado e heterogéneo, também os perfis dos artistas correspondem a uma diversidade de trajetórias e biografias. Deste modo, falamos de sujeitos que tanto podem ter uma trajetória associada ao graffiti ilegal, como podem deter educação artística formal, não sendo raros os casos em que acumulam ambas as condições. Também falamos, em termos profissionais, de situações variadas, que passam por artistas multifacetados trabalhando em diferentes áreas (design, ilustração, pintura, etc.) até aqueles que se especializaram na arte urbana. 
por uma estratégia política de valorização da arte urbana. Ou seja, o primeiro dificilmente aconteceria sem o segundo.

De modo a combater o graffiti ilegal que proliferava na cidade há uma década atrás, particularmente na sua zona histórica, o Departamento de Património Cultural da CML criou em 2008 a Galeria de Arte Urbana (GAU) que, inicialmente, consistia na disponibilização de um espaço próprio para a realização de pinturas a spray de forma autorizada. Subjacente a este modelo estava uma opção pelo diálogo com a comunidade dos graffiti writers e pela valorização do seu trabalho, criando condições para que este se pudesse desenvolver de forma autorizada. Genericamente, esta estratégia consistia numa forma de legitimação oficial do graffiti e da street art enquanto manifestações expressivas com valor estético e cultural, com um lugar na Lisboa contemporânea.

As ações da GAU foram-se diversificando e o seu papel foi fundamental para a solidificação deste meio artístico e para a emergência de um novo sector económico ligado a estas práticas. Convém, no entanto, realçar que a paisagem de Lisboa é marcada pela existência de uma quantidade assinalável de obras produzidas por artistas internacionais. Ou seja, este espirito de abertura institucional beneficiou claramente a comunidade artística local, mas fomentou também um espírito de cosmopolitismo e internacionalização que ficou bem patente em diferentes projetos organizados ou apoiados pela autarquia. Esta opção política teve impactos imediatos e duradouros na paisagem visual da cidade, com repercussões que se encontram bem evidentes na imagem que Lisboa projetou no exterior ao longo de uma década.

Entre as diversas iniciativas que a GAU tem vindo a desenvolver, destaca-se a galeria no espaço público existente no centro histórico da cidade, que organizou duas exposições anuais desde 2008 até 2014 (ver Figura 3), o apoio a distintas iniciativas de arte urbana ${ }^{9}$ e mais recentemente o festival internacional de arte urbana Muro. Este último evento teve três edições em três bairros da cidade, que se tornaram focos evidentes para ver arte urbana na capital e que são pontos obrigatórios dos roteiros turísticos neste campo. De salientar, ainda, um forte programa de divulgação destas expressões que envolve a publicação de uma revista e principalmente, a participação direta da

9 De destacar pelo impacto que tiveram na paisagem o "Crono", “40 anos, 40 murais", "Passeio literário da Graça", "Wool on tour" ou as diversas iniciativas de pintura mural da galeria Underdogs. 
GAU na elaboração do livro Street art Lisbon (2014), especialmente vocacionado para o mercado internacional e para turistas. Um website para a divulgação do projeto também foi criado, onde estão disponíveis imagens dos principais trabalhos existentes na cidade, mas onde também são oferecidas várias propostas de percursos pedestres em torno da arte urbana.

Este investimento da CML na arte urbana na capital tornou evidente que esta poderia ser uma mais-valia para a cidade, com repercussões em termos culturais, artísticos, simbólicos, mas também económicos. Este projeto pioneiro teve impacto em termos nacionais, sendo que nos últimos anos se multiplicaram iniciativas nesta área promovidas por autarquias de diferentes cidades portuguesas.

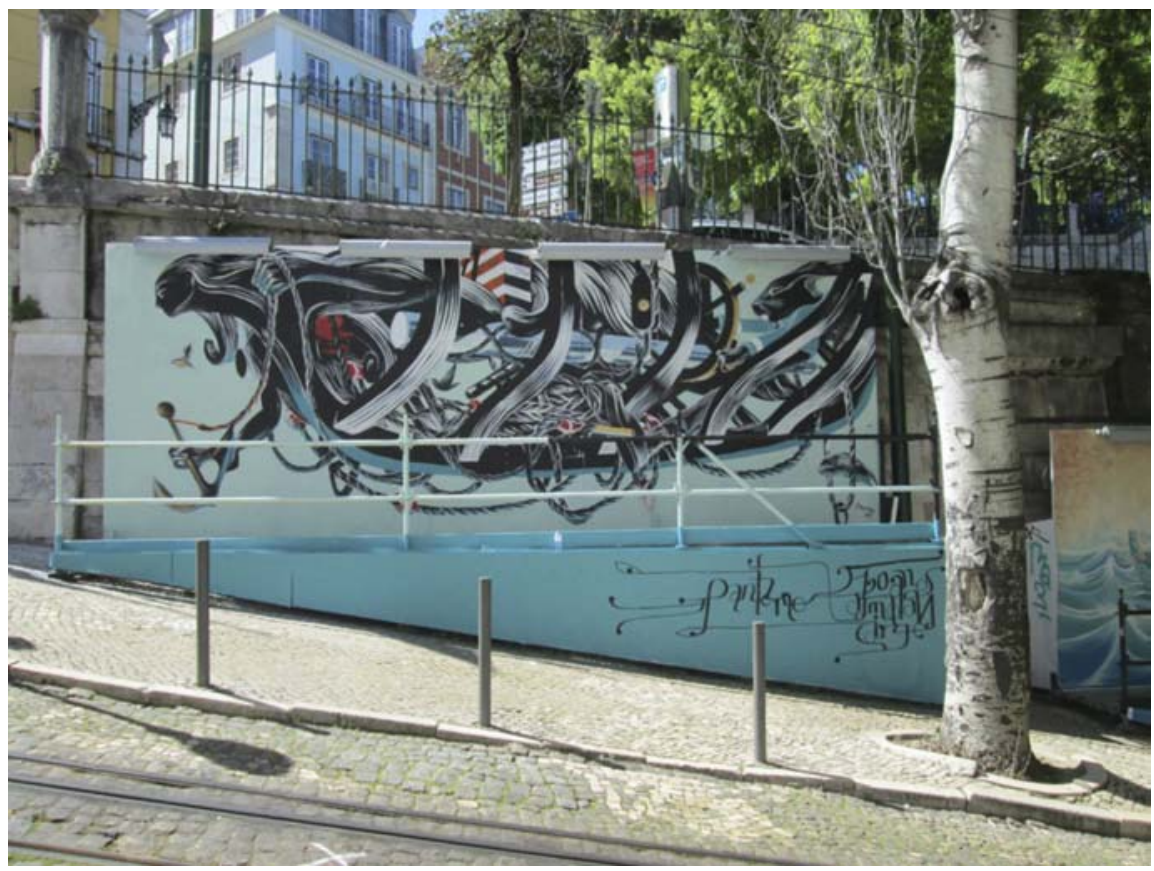

Figura 3. Painéis da GAU, Calçada da Glória, Lisboa (foto: Ágata Sequeira).

É curioso verificar que as entidades oficiais ligadas ao turismo também têm vindo a aperceber-se do potencial destas expressões, pelo que estas têm vindo 
a destacar a singularidade e qualidade deste movimento artístico em Portugal. Apesar de o seu papel mais direto na turistificação da arte urbana ser residual, o facto de assumirem que esta merece uma presença de destaque no património cultural e artístico do país é, do ponto de vista simbólico, extremamente importante. No website Visit Portugal, da responsabilidade do Turismo de Portugal, há uma página especificamente destinada à arte urbana, na secção Arte e Cultura, onde é claramente destacada esta forma de expressão:

Frequentemente somos surpreendidos por desenhos nas ruas, em painéis, nas fachadas e em grandes muros. São verdadeiras galerias a céu aberto, onde notáveis artistas de todo o mundo se propõem a dar vida e cor a lugares escondidos no tempo, com técnicas e mensagens diversas, fazendo assim a história de cada local. (Visit Portugal, [s.d.]).

Por seu turno, no website do Turismo de Lisboa na secção "Património e Cultura - Apenas em Lisboa”, encontramos a seguinte descrição:

Em quase todos os prédios ou ruas pode encontrar dignos representantes da arte geométrica ou figurativa que encontrou o seu expoente máximo em Portugal. A arte urbana de nomes mundialmente famosos, como Vhils; bem como arte ornamentada do estilo manuelino só se cruzam e conhecem neste palco solarengo que é Lisboa. Venha conhecer. (Turismo de Lisboa, [s.d.]).

Este último excerto é exemplificativo da retórica que se foi edificando em torno da arte urbana na capital. Tal narrativa está expressa não apenas na imprensa e meios de comunicação nacionais, mas também atravessa um conjunto de outros agentes. A cidade de Lisboa é representada como detendo algo de singular na medida em que convivem, de forma aparentemente harmoniosa, a tradição histórica mais monumental com os registos de contemporaneidade representados pela arte urbana.

\section{Os empreendedores locais}

A existência de um determinado objeto com potencial turístico numa cidade não é suficiente para que este obtenha sucesso do ponto de vista comercial. 
É fundamental a existência de agentes locais, de empreendedores dos mais diversos perfis que criem novas oportunidades de negócio dirigidos aos turistas que visitam a cidade e que, portanto, fabriquem um novo produto turístico. Na verdade, aquilo que se tem verificado em Lisboa é uma conjuntura extremamente favorável que se resume em dois pontos. Por um lado, o crescimento exponencial do turismo na cidade nos últimos anos e, por outro lado, um investimento sem precedentes na arte urbana ao longo de uma década, tendo como consequência uma considerável ampliação deste tipo de manifestações estéticas no espaço público urbano. Ou seja, estas duas tendências, que ocorreram praticamente em simultâneo, criaram as condições ideais para que um conjunto de empreendedores locais capitalizasse o potencial turístico da arte urbana concebendo diferentes roteiros (tours).

A relevância dos tours foi notada por Andron (2018) numa pesquisa recente. A autora, partindo do caso dos tours de street art em Londres argumenta que estes contribuem para a "afirmação, muralização e turistificação" de vários pontos daquela cidade. No caso de Lisboa, este é um fenómeno relativamente recente. Estas ofertas surgiram timidamente em 2013, sendo que atualmente contamos com cerca de uma dezena de operadores ativos. Estas são entidades que ou desenvolvem estes roteiros em paralelo com outros, ou se especializaram exclusivamente nesta área. De todo o modo, estamos a falar, na generalidade dos casos, de entidades de pequena dimensão, nalguns casos constituídas por apenas uma pessoa, que serve como guia turístico. Falamos de pequenas empresas de turismo, de associações informais, de guias individuais, de alojamentos locais e de galerias de arte que promovem os seus tours, etc.

O perfil dos responsáveis é muito distinto, desde o apaixonado e conhecedor profundo do meio até aos guias sem conhecimento particular na área e que foram lentamente desenvolvendo este ramo de atividade - e aprendendo mais sobre a arte urbana que é exibida, quer com ajuda de artistas, quer de forma mais autodidata. Porém, qualquer um dos guias exibirá inevitavelmente um discurso de "perito", guiando o olhar dos visitantes pelas peças que foram escolhidas para serem mostradas durante o percurso.

A presença online destes tours é um aspeto incontornável e que suporta também a ideia de que cada um oferece não só uma "experiência única", como também um guia que é uma "autoridade na matéria". Esta ideia é estrategicamente reforçada pela envolvente dos tours, no que respeita aos seus sistemas 
de reservas online, sites, blogs próprios, páginas dos tours e dos guias nas redes sociais e nas plataformas de classificação de experiências turísticas. ${ }^{10}$ Relativamente a estas últimas, os comentários positivos dos turistas em relação aos guias validam e legitimam a sua "autoridade" enquanto "peritos" na arte urbana local, tal como argumenta Andron (2018).

Por outro lado, a oferta de tours a nível de preços é também variada, indo de encontro aos diversos perfis dos turistas que as procuram. É ainda de notar que há uma certificação de algumas destes tours por parte da entidade de turismo local (Turismo de Lisboa), como se vê na Figura 4, em que o seu logotipo é exibido no panfleto de dois tours diferentes. Esta ideia de apoio institucional a tours de arte urbana também foi encontrada por Sabina Andron (2018), o que os legitima enquanto prática de turismo.

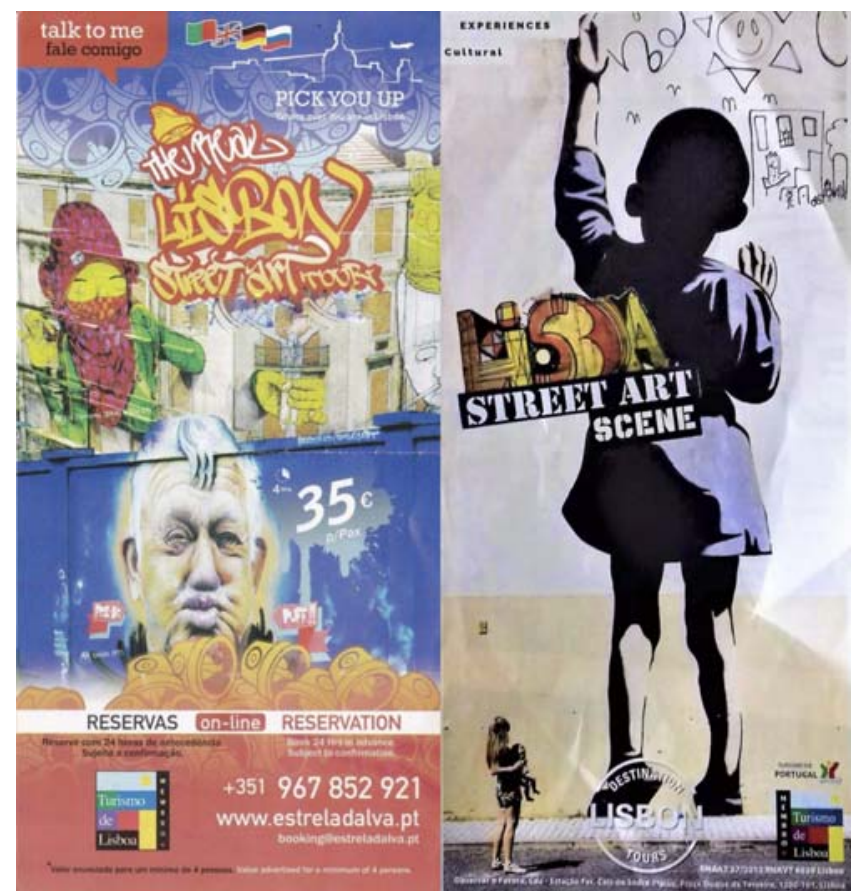

Figura 4. Exemplos de folhetos de tours de arte urbana em Lisboa.

10 Como o TripAdvisor e o Get Your Guide. 
Interessava-nos conhecer a realidade destas iniciativas, quais os seus protagonistas e o seu público. Deste modo participámos de alguns destes roteiros, procurando entender a forma como se inscreviam no território, a relação com a paisagem e o impacto que tinham no público. Paralelamente à participação nestes tours, foram realizadas entrevistas a diferentes responsáveis e guias, ${ }^{11}$ procurando compreender, por um lado, as motivações, objetivos e procedimentos associados à constituição destas ofertas turísticas, por outro lado, o sucesso destas iniciativas, o perfil dos turistas e os seus interesses.

Verificámos que o tipo de atividades desenvolvidas e a estrutura dos tours corresponde basicamente a dois tipos de ofertas. Há, por um lado, itinerários com uma natureza mais fechada, com roteiro predefinido e, por outro lado, circuitos de carácter mais aberto e flexível, que procuram dar resposta aos anseios e interesses particulares dos grupos de turistas. ${ }^{12}$ Sugerimos que há uma correlação entre o envolvimento do guia e o seu conhecimento profundo da realidade da arte urbana no território e o nível de flexibilidade nos percursos. A flexibilidade do roteiro também tende a ser dependente do perfil particular dos participantes.

A realidade existente na Área Metropolitana de Lisboa (AML) é suficientemente rica para permitir que existam diferentes ofertas e itinerários, apesar de haver uma geografia mais consensual e obrigatória, em torno das obras mais emblemáticas. Do conjunto de tours que encontrámos, existem walking tours, nas zonas centrais de Lisboa, e tours que exigem deslocação em transporte (da empresa ou alugada), sobretudo para os bairros situados em áreas mais periféricas, fora da zona tipicamente destinada ao turismo.

Relativamente à dimensão dos tours, no que respeita ao número de participantes, esta é muito variável, dependendo sobretudo das características logísticas de cada empresa e do percurso em causa. Um dos tours que atrai maior número de participantes - chegando a dezenas, em época alta - é precisamente

11 No que diz respeito aos empreendedores locais, foram identificadas as ofertas existentes na cidade em 2017 tendo sido todos contactados (12). Foram realizadas 8 entrevistas, o que corresponde a $67 \%$ dos agentes identificados. Em paralelo, participámos nalguns tours oferecidos por estes empreendedores, de modo a compreender melhor as dinâmicas existentes, a interação com o público e o envolvimento dos participantes.

12 Em termos geográficos os circuitos extravasam, por vezes, as fronteiras da cidade de Lisboa, percorrendo zonas limítrofes pertencendo a outros concelhos. 
um tour que se foca na zona central de Lisboa, no Bairro Alto. ${ }^{13}$ Os tours que levam os participantes às zonas periféricas da cidade, e que estão por isso dependentes do transporte de que dispõem, levam tendencialmente grupos menores. Um dos guias refere que o transporte de que dispõe é o seu próprio automóvel, pelo que nunca leva mais do que quatro visitantes nos seus tours, sendo o comum duas ou três pessoas.

O circuito territorial e as peças que são privilegiadas para cada tour dependem do guia e da sua avaliação. Há, todavia, exceções, no caso de se tratar de um guia profundamente ligado ao meio e que esteja a fazer um tour com visitantes também conhecedores e que pretendam um percurso mais personalizado em torno de um artista particular, por exemplo:

Sim, [os roteiros são] consoante o interesse. Há quem peça só graffiti do... há quem peça agora, por exemplo, Bordalo [II]. "Quero ver Bordalo, quero ver Bordalo. Sei que há um novo na LX [Factory], ok, então fazemos a LX." Fazemos o Centro Cultural... Há um em Telheiras, escondido debaixo de um viaduto, que muitas pessoas não sabem, há um na Avenida de Ceuta... então eu faço o roteiro e depois vamos e paramos, e falamos um bocadinho do trabalho dele, mas há muito, muito, muito interesse! Às vezes passa-nos um bocadinho ao lado, mas há pessoas que só querem ver isto. (Nuno de Palma, Get Lost Go Local Tours).

Daí que faça sentido invocar aqui, mais uma vez, a pesquisa de Andron (2018) sobre os tours de street art. Segundo a autora, estas iniciativas contribuem para construir e legitimar uma certa "cena" local da arte urbana, através de um discurso de "autoridade" sobre a matéria. A este papel de legitimação do mundo da arte urbana, por parte destes tours, corresponde também uma delimitação desse mundo e uma atribuição de capital simbólico a determinados artistas. Estas observações confirmam a existência de "geografias morais" na cidade (McAuliffe, 2012) e a construção de itinerários turísticos que favorecem as obras autorais e legitimadas (Andron, 2018) ao invés de intervenções anónimas. Esta seleção criteriosa das peças conduz a uma certa "cultura de fama artística":

13 Bairro Alto é um dos bairros históricos, no coração de Lisboa. 
Guides will almost always select work whose authorship they can attribute, leaving anonymous marks outside the scope of their discourse, and cutting out an important part of the wall writing culture to focus on the street art. By singling out certain works and naming their makers, the tours contribute to the creation of a culture of artistic fame. They parade a spectacle of carefully curated images in front of participants, while exercising their authority to decide on artistic worth. The decision to include certain images implies the exclusion of everything else [...]. (Andron, 2018, p. 1042).

É consensual, entre os entrevistados, a avaliação do sucesso das iniciativas e a reiteração do potencial de crescimento representado por este ramo de atividade. Isto deve-se não apenas ao alargamento da procura turística, mas também a um maior interesse pela arte urbana, sendo que é cada vez mais comum surgirem turistas conhecedores deste campo de expressão artística:

Cada vez mais os artistas são reconhecidos lá fora, há muita presença nos órgãos de comunicação social, nas redes sociais. Há cada vez mais colecionadores, também. E portanto eu já tenho um público muito mais especializado do que tinha no princípio. (Vasco Rodrigues, Estrela d'Alva).

Comum ao discurso dos empreendedores turísticos é a criação de propostas que desafiem o modelo do turismo massificado, dos itinerários padronizados e inflexíveis, de um turismo marcado por highlights. Os tours de arte urbana servem de pretexto para mostrar uma "Lisboa diferente", fora dos circuitos turísticos habituais. Este elemento confirma aquilo que tinha sido por nós anteriormente afirmado, que o turismo cultural está associado a uma certa busca pela autenticidade. Ou seja, a natureza autêntica dos lugares e experiências é, por si só, um valor importante. Como refere o nosso entrevistado, estes tours permitem contornar a imagem estereotipada da cidade e o consumo turístico massificado:

É uma curiosidade também por ver outro tipo de cidade, que não a cidade histórica, a cidade velhinha, a cidade com as velhinhas à janela a estender roupa... porque essa é a imagem que nós promovemos... (Nuno de Palma, Get Lost, Go Local). 
Em grande medida esta retórica também se verifica em função da geografia da arte urbana na AML, uma vez que existem diversos núcleos com elevada concentração de arte urbana que se situam em bairros periféricos e marginalizados da cidade. A ideia de "autenticidade", de uma "cidade alternativa" e "desconhecida" dos circuitos turísticos habituais está, aliás, também presente nos próprios materiais promocionais. Por exemplo, podemos ler num flyer de um tour de arte urbana as seguintes palavras:

Follow us around $50 \mathrm{~km}$ in the city of Lisbon boundaries for a type of Tour we guarantee you never experienced before. The Street Art Tour will take you to an alternative getaway through the most unknown places of the city. (Flyer do Street Art Tour da Destination Tours Lisbon).

Este aspeto ilustra em que medida os tours de arte urbana contribuem para que a cidade de Lisboa seja conotada com um lugar de diversidade, cosmopolita, moderno e, portanto, apelativo a um sector turístico porventura diferente daquele que privilegia os circuitos clássicos. A autenticidade está, assim, aliada a uma certa ideia de alteridade, diferença e exotismo, que procura exibir uma Lisboa que não se resume ao cartão postal, ao património histórico monumental, aos seus bairros típicos e aos santos populares. À imagem estereotipada promovida pelos diferentes agentes turísticos convencionais, estes empreendedores contrapõem uma outra imagem, buscando construir um novo nicho de mercado. Os clientes habituais destes tours, segundo os nossos entrevistados, procuram experiências e territórios distintos, buscam algo ainda não totalmente explorado e massificado. Daí que estas ofertas surjam em resposta a necessidades que foram criadas e a uma procura por parte dos turistas:

Portanto a partir daí, comecei a ter pedidos só de street art. Eu quase que não fazia “Lisboa Antiga", não fazia “Lojas Históricas"... Fazia street art e depois metia uma lojinha histórica pelo meio. Portanto passou a ser o oposto. Depois modifiquei um pouco o site, portanto, abri um tour só de street art, porque vi que de facto, fazia [sentido]. (Nuno de Palma, Get Lost, Go Local Tours).

Referimos que a procura destes tours tem vindo a crescer. No que respeita ao perfil dos turistas, estes são basicamente estrangeiros, com idades variáveis. 
Podemos, todavia, identificar basicamente dois perfis distintos. De acordo com os nossos entrevistados, encontramos, por um lado o "turista curioso" mas leigo na matéria, que abrange a maioria dos clientes dos tours e, por outro lado, o "turista especializado", que é adepto desta expressão artística, que faz uma exploração prévia sobre o meio e a realidade local. Geralmente para o "turista curioso" esta é apenas mais uma atividade entre outras desenvolvidas na sua visita à cidade, enquanto que para os turistas mais especializados, esta é uma experiência obrigatória e central da sua visita. Estes, inclusive, manifestam por vezes o interesse em conhecer pessoalmente determinado artista. Assim, é possível que os guias dos tours de arte urbana, os que melhor conhecem o meio, acabem por desempenhar também o papel de intermediários entre artistas e potenciais compradores estrangeiros, interessados no seu trabalho:

Há sempre esta hipótese de saber o que é que está a acontecer ou então já é um turista que já sabe muito. E que é colecionador e que só quer ver obras de uma certa pessoa e quando vem ao tour e quando marca o tour diz mesmo "ok eu quero ver peças", já me aconteceu "eu quero ver peças da Tamara Alves, mas eu quero conhecer a Tamara Alves também" ou "eu quero ver graffiti de rua mas gostava de ver alguém a pintar". Isso depois através dos meus conhecimentos eu consigo sempre conciliar, não só o colecionador contactar com o artista e comprar diretamente a ele que já aconteceu ou ver alguém a pintar. Ter essa mais-valia de conhecer alguém que pinta e vê-los a pintar. (Vasco Rodrigues, Estrela d'Alva).

Este é um exemplo claro da forma como os guias dos tours de street art contribuem para configurar o campo. A sua atividade pode ter consequências não apenas no sentido da comodificação de uma expressão artística urbana para fins de turismo, mas também na medida em que podem viabilizar um mercado neste mundo da arte, ao assumirem o papel de intermediários entre artistas e turistas (eventuais colecionadores e compradores). Não se trata, portanto, de meros observadores do panorama local da arte urbana:

Eu levei um grupo de doze pessoas, eram duas carrinhas quando os amigos todos se juntaram e renovaram aqui as Amoreiras, estavam lá todos a pintar e eu levei um grupo e no grupo havia dois colecionadores que imediatamente compraram 
coisas. Os artistas não tinham lá coisas mas combinaram logo... visitar os ateliers deles ou encontrar-se com eles no hotel onde eles estão e comprar coisas. Portanto eu gosto sempre dessa vertente porque acaba por ser também [importante]. (Vasco Rodrigues, Estrela d'Alva).

Todavia, estas atividades geram, por vezes, atritos. A reação por parte dos artistas à sua atividade nem sempre é positiva. Se alguns não veem nos tours uma atividade que ameace a integridade do seu trabalho enquanto artistas, outros não a consideram de todo uma atividade bem-vinda. ${ }^{14}$ Esta situação também já tinha sido relatada por Bengtsen (2014), que destaca as ambiguidades que rodeiam o turismo de arte urbana, pelo facto de institucionalizarem e mercantilizarem algo que é de natureza informal, democrática e espontânea. Os próprios guias têm a noção desta ambivalência e dos impactos que a sua atividade pode ter na cidade e na prática dos artistas:

Acho que é diferente, quando chegamos 30 pessoas e olhamos para alguém a trabalhar, epá, a pessoa sente-se assim um bocadinho melindrada: "O que é isto?" A pessoa sente-se um bocadinho como no circo. Sim, sim, é um circo. E Lisboa às vezes é um circo. Há um graffiti do fado onde eu passava muitas vezes e eu agora já não consigo passar! Explico, [...] há um graffiti, há um mural do fado feito por vários artistas, um deles é o Hugo Makarov, tem a Maria Severa, o Fernando Maurício... [...] Esse grafiti é um ex-libris, toda a gente me pergunta onde é que aquilo é! E eu agora já não consigo fazer a rotazinha de subir as escadas e ir explicar, porque tenho grupos constantes parados ali! Portanto... não é... não é bom! (Nuno de Palma, Get Lost Go Local Tours).

Finalmente, um aspeto que importa aqui incluir é o que diz respeito à articulação com os meios digitais que, como Andron (2018) relatou, têm um papel importante. Podemos dizer que, atualmente, o turismo que se faz não assenta apenas nas atividades realizadas fisicamente (offline), mas também no mundo digital (online). Não falamos apenas das pesquisas que são realizadas, das leituras de blogs ou websites, das reservas (hotéis, tours, etc.), mas também da

14 Um dos guias relatou uma situação em que um artista o acusou de "estar a fazer dinheiro à sua custa" com os tours. 
produção de conteúdos diversos (vídeos, imagens, textos...) que são colocados e distribuídos através de canais diversos, nomeadamente nas redes sociais. Ou seja, o turismo assume uma dimensão de hibridismo que importa frisar. Esta é uma dimensão que está muito presente nas empresas que organizam tours de street art. Os turistas cumprem um papel significativo na sua promoção, através da partilha de textos e sobretudo de imagens nas redes sociais (Instagram, Facebook, Pinterest, etc.), podendo fazer a ligação para a presença online das próprias tours e para as plataformas de reviews (como o TripAdvisor e o Get Your Guide). Num dos flyers que encontrámos de um tour de arte urbana em Lisboa, os visitantes, os offline explorers, são, aliás, explicitamente convidados a partilhar imagens da sua visita nas redes sociais - o que é, claramente, uma forma de promoção do próprio tour:

A real-time Pinterest gallery of the best art in Lisbon! This tour was created for offline explorers. Create new boards and pin the best pictures of the renowned artists. Show your friends that getting around a roofless museum is out of the ordinary! (Destination Tours Lisbon).

\section{Conclusão}

Em jeito de conclusão podemos afirmar que a turistificação da arte urbana é uma tendência global, funcionando a diferentes ritmos em função das características das cidades. Todavia, parece indiscutível que, atualmente, em cidades como Berlim, São Paulo, Londres ou Buenos Aires, a arte urbana é uma parte fundamental da paisagem e identidade da cidade, como está explicito em diferentes guias turísticos. Esta é uma dinâmica recente em que estão envolvidos distintos atores sociais. Este processo acompanha outros que passam pelo crescente interesse que este movimento artístico desperta junto de diferentes públicos, facto que resulta da maior visibilidade e institucionalização destas práticas artísticas. Os media, as entidades públicas e o mundo das artes têm tido um papel de destaque nesta dinâmica. Ou seja, a valorização deste movimento e dos seus agentes implica que as obras passem a ser tidas como um património das cidades, um elemento de valorização do espaço público e da paisagem citadina. Daí que, à semelhança dos monumentos existentes 
no espaço público, do edificado histórico, ou da arquitetura de qualidade, estas peças representem um valor acrescentado para a cidade. Como tal, não é de estranhar que despertem o interesse dos visitantes.

A este respeito Lisboa é um bom estudo de caso. Tivemos oportunidade de acompanhar este processo ao longo do tempo, registando aquilo que foi a gradual legitimação e consagração desta expressão artística por parte das autoridades locais, a lenta profissionalização do campo artístico e a alteração da paisagem na cidade (Campos, 2010, 2015; Campos; Sequeira, 2018; Sequeira, 2015, 2016a, 2016b). O nosso acompanhamento do processo levou-nos a propor uma análise que tem em consideração aqueles que consideramos os atores-chave que participam da turistificação. Por um lado, definimos aqueles que são os atores internacionais e translocais, nomeadamente no sector da comunicação, que constroem imaginários e narrativas em torno dos destinos, que fabricam produtos e experiências de consumo turístico. A este nível tivemos em consideração os media internacionais (genéricos e especializados) e os cada vez mais importantes media sociais. Por outro lado, definimos aqueles que são os atores locais, compreendendo as autoridades públicas (locais e nacionais) e os empreendedores turísticos.

Da nossa análise verificamos que se tem construído toda uma narrativa que favorece a turistificação da arte urbana na capital. Esta é uma narrativa que é partilhada pelos diferentes atores, que frisa a importância da arte urbana na capital portuguesa, concedendo-lhe um papel fundamental para a identidade $e$ imagem da cidade. Esta é uma imagem fabricada em torno de duas polaridades que, aparentemente, convivem em harmonia e concedem a Lisboa a sua singularidade. Por um lado, a polaridade relativa ao passado e à tradição, acentuando as riquezas históricas e a monumentalidade, próprios de uma capital de um antigo império colonial, mas também as riquezas da cultura popular presentes na gastronomia ou na música (por exemplo o fado). Por outro lado, um polo da contemporaneidade, que acentua a dinâmica vibrante de uma cidade cosmopolita, culturalmente heterogénea, com uma vida artística e cultural intensa, onde se encontra o melhor que se produz em termos de arquitetura, arte pública e arte urbana.

Esta narrativa coincide com um incremento rápido do turismo em Portugal, particularmente nas suas maiores cidades (Lisboa e Porto). Este crescimento é evidente nos últimos anos, especialmente no período que se seguiu à crise 
económica que assolou Portugal, tendo o turismo um papel cada vez mais relevante na economia do país e no seu crescimento económico. Deste modo, múltiplas ofertas turísticas foram surgindo na cidade de Lisboa, acompanhando o ritmo do turismo. Fruto de uma confluência de fatores que foram analisados ao longo deste artigo, verificamos que a arte urbana se converteu num produto turístico distintivo e com claro potencial de expansão.

\section{Referências}

ANDRON, S. Selling streetness as experience: the role of street art tours in branding the creative city. The Sociological Review, v. 66, n. 5, p. 1036-1057, 2018.

AUSTIN, J. More to see than a canvas in a white cube. For an art in the streets. City, v. 14, n. 1, p. 33-47, 2010.

BANET-WEISER, S. Convergence on the street. Cultural Studies, v. 25, n. 4-5, p. 641-658, 2011.

BECKER, H. Mundos da arte. Lisboa: Livros Horizonte, 2010.

BENGTSEN, P. The street art world. Lund: Almendros de Granada Press, 2014.

CAMPOS, R. a cidade?: uma abordagem etnográfica do graffiti urbano. Lisboa: Fim de Século, 2010.

CAMPOS, R. Graffiti writer as superhero. European Journal of Cultural Studies, v. 16, n. 2, p. 155-170, 2013.

CAMPOS, R. Graffiti, street art and the aestheticization of transgression. Social Analysis, v. 59, n. 3, p. 17-40, 2015.

CAMPOS, R. O espaço e o tempo do graffiti e da street art. Cidades, Comunidades e Território, n. 34, p. 1-16, June 2017.

CAMPOS, R.; SEQUEIRA, A. O mundo da arte urbana emergente: contextos e atores. Todas as Artes: Revista Luso-Brasileira de Artes e Cultura, v. 1, n. 2, p. 70-93, 2018.

CAMPOS, R.; SEQUEIRA, A. Urban art touristification: the case of Lisbon. Tourist Studies, Sept. 2019. DOI: https://doi.org/10.1177/1468797619873108.

CASTLEMAN, C. Getting up: subway graffiti in New York. Cambridge: MIT Press, 1982. CHUNG, N.; KOO, C. The use of social media in travel information search. Telematics and Informatics, v. 32, n. 2, p. 215-229, 2015. 
COOPER, M.; CHALFANT, H. Subway art. London: Thames \& Hudson, 1984.

COZZOLINO, F. The "artification" process in the case of murals in Sardinia. In: CAMPOS, R.; SARMENTO, C. (ed.). Popular and visual culture: contexts of design, circulation and consumption. Cambridge: Cambridge Scholars Publishing, 2014. p. 167-190.

DU CROS, H.; MCKERCHER, B. Cultural tourism. London: Routledge, 2002.

ESTRATÉGIA Turismo 2027. Lisboa: Turismo de Portugal, 2017. Disponível em http://estrategia.turismodeportugal.pt/sites/default/files/Estrategia_Turismo_Portugal_ET27.pdf. Acesso em: 3 maio 2018.

FERRELL, J. Crimes of style: urban graffiti and the politics of criminality. Boston: Northeastern University Press, 1996.

JAŻDŻEWSKA, I. Murals as a tourist attraction in a post-industrial city: a case study of Łódź (Poland). Tourism, v. 27, n. 2, p. 45-56, 2017.

KOSTER, R.; RANDALL, J. E. Indicators of community economic development through mural-based tourism. The Canadian Geographer, v. 49, n. 1, p. 42-60, 2006.

KRAMER, R. Painting with permission: legal graffiti in New York City. Ethnography, v. 11, n. 2, p. 235-253, 2010.

LEWISOHN, C. Street art: the graffiti revolution. New York: Abrams, 2008.

MACDONALD, N. The graffiti subculture: youth, masculinity and identity in London and New York. Basingstoke: Palgrave Macmillan, 2001.

MARQUES, L.; RICHARDS, G. The dimensions of art in place narrative. Tourism Planning and Development, v. 11, n. 1, p. 1-12, 2014.

MCAULIFFE, C. Graffiti or street art? Negotiating the moral geographies of the creative city. Journal of Urban Affairs, v. 34, n. 2, p. 189-206, 2012.

MCDOWELL, S. Selling conflict heritage through tourism in peacetime Northern Ireland: transforming conflict or exacerbating difference?. International Journal of Heritage Studies, v. 14, n. 5, p. 405-421, 2008.

MIGUEL-MOLINA, M. et al. Creative cities and sustainable development: mural-based tourism as a local public strategy. Dirección y Organización, n. 50, p. 31-36, 2013.

MOKRAS-GRABOWSKA, J. Art-tourism space in Łódź: the example of the Urban Forms Gallery. Tourism, v. 24, n. 2, p. 23-30, 2014. 
MOORE, R. How down-at-heel Lisbon became the new capital of cool. The Guardian, 16 Apr. 2017. Disponível em: https://www.theguardian.com/artanddesign/2017/ apr/16/lisbon-new-capital-of-cool-urban-revival-socialist-government-poor-antonio-costa. Acesso em: 18 fev. 2018.

MORRIS, J. Street art - popular tourism attractions in Berlin. Tourism Review News, 3 Apr. 2017. Disponível em: https://www.tourism-review.com/unique-tourism-attractions-in-berlin-news5345. Acesso em: 3 maio 2018.

MOULD, O. Urban subversion and the creative city. London: Routledge, 2015.

NEW travel trend: Exploring cities through graffiti and street art. Eturbonews - Global Travel Industry News, 7 Oct. 2017. Disponível em: https://www.eturbonews.com/167067/ new-travel-trend-exploring-cities-graffiti-street-art. Acesso em: 1 out. 2018.

OBSERVATÓRIO DO TURISMO DE LISBOA. Dados de Dezembro de 2017. Lisboa: Turismo de Lisboa, 2017. Disponível em https://www.visitlisboa.com/sites/default/ files/2018-02/RTL169-OBS.pdf. Acesso em: 3 maio 2018.

POON, S.T.F. Street murals as a unique tangible cultural heritage: a case study of artifact value preservation. International Journal of Cultural and Creative Industries, v. 4, n. 1, p. 48-61, Nov. 2016.

PORRITT, R. Street art in Europe: 5 European cities with awesome graffiti. The New European, 1 March 2017. Disponível em: http://www.theneweuropean.co.uk/culture/ street-art-in-europe-5-european-cities-with-awesome-graffiti-1-4910531. Acesso em: 18 fev. 2018.

RICHARDS, G. Cultural tourism: a review of recent research and trends. Journal of Hospitality and Tourism Management, v. 36, p. 12-21, 2018.

RIZA, M.; DORATLI, N.; FASLI, M. City branding and identity. Procedia-Social and Behavioral Sciences, v. 35, p. 293-300, 2012.

ROJO, J.; HARRINGTON, S. Exploring Lisbon as a street art tourist. Huffington Post, 23 July 2014 (updated 6 Dec. 2017). Disponível em: https://www.huffingtonpost.com/ jaime-rojo-steven-harrington/lisbon-street-art_b_5611789.html. Acesso em: 18 fev. 2018.

SALADINO, E. Top 10 cities for street art around the world. Fodor's Travel, 7 June 2013. Disponível em: https://www.fodors.com/news/photos/top-10-cities-for-street-art-around-the-world. Acesso em: 3 maio 2018.

SANTAMARINA-CAMPOS, V. et al. Digital integration of the European street art: tourism, identity and scientific opportunities. In: KATSONI, V;; UPADHYA, A.; STRATIGEA, A. (ed.). Tourism, culture and heritage in a smart economy: Third International Conference IACuDit, Athens 2016. Cham: Springer International Publishing, 2017. p. 35-47. 
SCHACTER, R. The ugly truth: street art, graffiti and the creative city. Art and the Public Sphere, v. 3, n. 2, p. 161-176, 2014.

SEQUEIRA, A. Letting the walls of the city speak: the route of a sociological research project on Lisbon's street art. Street Art and Urban Creativity Journal, v. 1, n. 2, p. 82-88, Nov. 2015.

SEQUEIRA, A. A cidade é o habitat da arte: street art e a construção de espaço público em Lisboa. 2016. Tese (Doutoramento em Sociologia) - Instituto Universitário de Lisboa, Lisboa, 2016a.

SEQUEIRA, A. Ephemeral art in impermanent spaces: the effects of street art in the social construction of public space. In: GUERRA, P.; COSTA, P.; NEVES, P. S. (ed.). Urban interventions: street art and public space. Lisboa: Urban Creativity (internacional), 2016b. p. 65-74.

SHAPIRO, R. Avant-propos. In: SHAPIRO, R.; HEINICH, N. (dir.). De l'artification: enquêtes sur le passage à l'art. Paris: EHESS, 2012. p. 15-26.

SKINNER, J.; JOLLIFFE, L. Wall-to-wall coverage: an introduction to murals tourism. In: SKINNER, J.; JOLLIFFE, L. (ed.). Murals and tourism: heritage, politics and identity. London: Routledge, 2017. p. 3-24.

SMITH, M. K. Issues in cultural tourism studies. London: Routledge, 2003.

STREET art Lisbon. Lisboa: Câmara Municipal de Lisboa: Zest, 2014.

TURISMO DE LISBOA. Apenas em Lisboa. Disponível em: https://www.visitlisboa. com/pt-pt/c/patrimonio-cultura/apenas-em-lisboa. Acesso em: 8 maio 2018.

TURISMO DE PORTUGAL. European cities marketing benchmarking report 2014. 2015. Disponível em: http://www.turismodeportugal.pt/Portugu\%C3\%AAs/AreasAtividade/desenvolvimentoeinovacaol/Pages/european-cities-marketing-benchmarking-report-2014.aspx. Acesso em: 4 set. 2015.

VISIT PORTUGAL. Arte urbana em Portugal. [s.d.]. Disponível em: https://www.visitportugal.com/pt-pt/content/arte-urbana-em-portugal.Acesso em: 3 maio 2018.

WACLAWEK, A. Graffiti and street art. London: Thames \& Hudson, 2011.

WORLD TOURISM ORGANIZATION. Tourism and culture synergies. Madrid, 2018. DOI: https://doi.org/10.18111/9789284418978.

XIANG, Z. et al. Adapting to the internet: trends in travelers' use of the web for trip planning. Journal of Travel Research, v. 54, n. 4, p. 511-527, 2015. 
YOUNG, A. Street art, public city. London: Routledge, 2014.

ZENG, B.; GERRITSEN, R. What do we know about social media in tourism? A review. Tourism Management Perspectives, v. 10, p. 27-36, 2014.

Recebido: 10/10/2018 Aceito: 15/04/2019 | Received: 10/10/2018 Accepted: 4/15/2019

(c) (i) Esta obra está licenciada com uma Licença Creative Commons - Atribuição 4.0 Internacional This work is licensed under a Creative Commons Attribution 4.0 International License. 